\title{
Integrating quality of life assessments in student clinical learning experience / Intégration d'une évaluation de la qualité de vie dans les situations d'apprentissage clinique des étudiantes
}

Tracy Stephen

Trinity Western University, tracy.stephen@twu.ca

Andrea Orr

Trinity Western University, Andrea.Orr@twu.ca

Landa Terblanche

Trinity Western University, landa.terblanche@twu.ca

Richard Sawatzky

Trinity Western University, rick.sawatzky@twu.ca

Follow this and additional works at: https://qane-afi.casn.ca/journal

Part of the Other Nursing Commons

\section{Recommended Citation}

Stephen, Tracy; Orr, Andrea; Terblanche, Landa; and Sawatzky, Richard (2019) "Integrating quality of life assessments in student clinical learning experience / Intégration d'une évaluation de la qualité de vie dans les situations d'apprentissage clinique des étudiantes," Quality Advancement in Nursing Education - Avancées en formation infirmière: Vol. 5: Iss. 1, Article 4.

DOI: https://doi.org/10.17483/2368-6669.1182

This Article is brought to you for free and open access by Quality Advancement in Nursing Education - Avancées en formation infirmière. It has been accepted for inclusion in Quality Advancement in Nursing Education - Avancées en formation infirmière by an authorized editor of Quality Advancement in Nursing Education - Avancées en formation infirmière. 


\section{Introduction}

The World Health Organization (WHO) defines quality of life (QOL) as an "individual's perception of their position in life in the context of the culture and value systems in which they live and in relation to their goals, expectations, standards and concerns" (2017, p. 1). QOL is affected complexly by the person's physical and psychological health, personal beliefs, social relationships, and their relationship to prominent features in their environment (World Health Organization, 2017). In an aging society with increasing chronic illness prevalence, cure is not the expected outcome; instead, palliation of symptoms and enhancing QOL become the treatment focus. A comprehensive assessment of QOL is an important foundation of person-centred care (Ohlen et al., 2017). Attention to concepts of person- and patient-centred care have gained prominence as health care providers increasingly recognize the importance of individualized plans of care (Zhao, Gao, Wang, Liu, \& Hao, 2016). Within the past decade, a series of initiatives have been implemented in Canadian health care that focus on establishing the person at the centre of health system reform and improving QOL (Zhao et al., 2016). Although making patients "feel better" is the focus of much clinical care, patient reports of their functioning and wellbeing are infrequently collected routinely and integrated in a standardized form in clinical practice (Snyder et al., 2012). While standardized assessments of vital signs, lab values, and imaging studies are taught in labs and clinical practice during undergraduate nursing education, there has been little emphasis on teaching QOL assessments based on the use of standardized instruments. To address this gap in nursing education, we applied a transformational learning framework by designing a qualitative interpretive descriptive study that involved a QOL assessment assignment. The student experiences and perspectives were used as a starting point for integrating teaching on QOL assessments into undergraduate nursing curriculum.

\section{Background}

There is significant interest and momentum towards using standardized instruments, such as patient-reported outcome measures (PROMs), to facilitate QOL assessments in nursing practice. QOL assessment instruments (including PROMs) consist of standardized sets of questions used to obtain information from patients and family caregivers about health outcomes relevant to their QOL, including symptoms, functional status, health status, and psychological, social, and existential wellbeing (Fayers \& Machin, 2013). These instruments provide patients and family caregivers with the opportunity to interact with the health care team and answer questions about their symptoms and experiences with their care. There are many QOL assessment instruments available, over 1500 are indexed in various databases (e.g., PROQUOLID ${ }^{\mathrm{TM}}$ ). These QOL instruments are increasingly being integrated into clinical practice, including in outpatient clinics, surgical care, palliative care, cancer care, residential care, and community-based services (Greenhalgh, 2009).

The increased use of QOL assessment instruments in clinical practice is an important component of person-centred care, which can be defined as actively enabling the patient to share their personal illness narrative (Ohlen et al., 2017). Allowing the patient to share their narrative is enhanced by the creation of a partnership between the patient and their health care professional(s), followed by documentation of the patient's narrative and plan of care for coordinated team actions (Ekman et al., 2011). Several studies and systematic reviews have shown that utilizing standardized QOL assessment instruments in patient care can enable professionals to efficiently assess and address fluctuations in the patient's concerns (Greenhalgh \& Meadows, 1999; Marshall, Haywood, \& Fitzpatrick, 2006). With the use of QOL assessment instruments, patients may feel 
that health care professionals are more involved in their care because they are showing interest in obtaining the patient's perspectives on their own health and wellbeing. Along with gaining the patient perspective, QOL assessment instruments can be used to assess the impact of health care interventions on patient health and QOL, assist with guiding resource allocation, and evaluate the effects of service changes (Dawson, Doll, Fitzpatrick, Jenkinson, \& Carr, 2010). Despite the case for QOL assessments being strong, the integration of QOL assessment instruments in routine practice has proved challenging (Catania et al., 2015; Etkind et al., 2015).

Previously conducted literature reviews reveal a gap in knowledge of how to integrate QOL information into clinical workflow and decision-making for practitioners (Basch \& Abernethy, 2011; Greenhalgh, Long, \& Flynn, 2005). Although QOL assessment instruments may be used to collect valuable information, clinicians do not consistently apply this information to patient care. Some believe that education for clinicians on how to use and act on QOL assessments will support patient engagement and participation in shared decision-making (Santana et al., 2015). According to Detmar, Muller, Wever, Schornagel, and Aaronson (2001), the most significant factor influencing QOL assessments with the patient was the clinician's perception of their responsibility to do so. Antunes, Harding, and Higginson (2014) believe that education for health care professionals regarding QOL assessments prior to implementation is needed to ensure effective use of the QOL assessment instruments and enhance person-centred care.

It is believed that QOL assessments will increasingly become an expectation in all areas of nursing practice. Therefore, nurses must understand the role of these assessments as a routine part of patient care (Ousey \& Cook, 2011). Nurses can, and should, take leadership roles in the implementation and use of QOL assessment instruments as the principles behind the instruments are in keeping with the patient-centred philosophy of nursing (Barham \& Devlin, 2011). Despite the fact that the overall implementation of interventions focused on QOL assessments results in improved patient outcomes (Catania et al., 2015) and the corresponding importance of nurses to understand the role of QOL assessments in routine practice, they have not been widely integrated into nursing education. For example, the practice of QOL assessments is not widely addressed in undergraduate nursing textbooks.

Transformational learning provides a valuable framework for teaching and learning in the clinical setting. According to Mezirow, the founder of transformative learning theory, learning takes place as a person forms and reforms meaning in their life, with the goal to develop "autonomous thinking" (Mezirow, 1997). Transformational learning experiences cause the learner to become critical of his or her beliefs and how they affect the manner in which the learner makes sense of their world (Cranton, 2006; Stansberry \& Kymes, 2007). The design elements of transformative learning go beyond skill acquisition to affect changes in frames of reference because individuals step out of their habits (Choy, 2009). As such, transformational learning promotes the learners' valuing of new knowledge for their own practice. Over time, the adaptation and evolution of this knowledge will take place within their own work context and professional practice. The transformative learning approach overcomes feelings of coercion, exposes distorting self-deceptions, promotes openness, and provides a vehicle for expressing empathy and concern about how others think and feel.

McWilliam (2007) points out that transformational learning becomes a forum for learners to weigh new knowledge and assess arguments to alternative directions, consider the context of ideas, and more critically reflect on assumptions, including their own. Mezirow (1997) further describes how transformative learning takes place through experience, reflection, and discourse. 
In applying this theory to nursing education, emphasis is placed on learning through clinical experience. The educator is viewed as a learning companion who helps the learner recognize their own expertise and experience (Cranton \& Wright, 2008). Individuals are asked Socratic questions that encourage re-examination of their beliefs and values - creating doubt that leads to change in perceptions. The educator encourages students to engage in critical reflection, dialoguing, being sensitive to difference, being compassionate in caring, and using creative thinking (Tennant, 2005).

Building on the foundations of transformational learning, the inclusion of QOL assessments in clinical learning can afford students the opportunity to reflect on their clinical experiences and make their own interpretations of meaning (purposes, beliefs, judgements, and feelings) in their nursing practice. Students are further encouraged to reflect on their own assumptions underlying their interpretations of their clinical experiences by entering into dialogue focused on the concerns and experiences of patients and family caregivers. Through this process, the clinical learning environment offers valuable opportunities to think in new and different ways and to trigger new insights and critical reflection. Ongoing critical reflection creates needed introspective opportunities for students to identify and analyze their feelings of discomfort, stress, and anxiety while questioning the integrity of one's assumptions and beliefs, which results in transformation or change in one's perspective (Keating, 2006; Melrose, Park, \& Perry, 2015).

In order to prepare new nurses to use standardized QOL assessment instruments, it is imperative that competencies, including knowledge, skills, and attitudes, pertaining to the use of these tools be integrated into undergraduate nursing education. Little is known about how students perceive the use of QOL assessments in their clinical practice. We therefore designed a qualitative study as an initial step toward addressing this gap in knowledge by integrating a QOL assessment assignment into an existing senior-level undergraduate nursing course and reviewing students' reflective feedback. The research question in this study was: "What are the experiences and perspectives of fourth-year undergraduate nursing students regarding the use of standardized QOL assessment instruments in their clinical learning experience on a surgical unit with patients having life-limiting conditions?"

\section{Description of the Assignment}

The authors developed an assignment to help students build competency regarding QOL assessment instruments. The objective was for students to reflect on their experiences using QOL assessment instruments on a surgical nursing unit with patients who have chronic life-limiting conditions (e.g., cancer, COPD, HF, MS, CVA, or general frailty). Students were expected to review the QOL assessment information gained from the patient and, from this gathered information, along with further assessment and clinical judgment, identify potential interventions and resources that addressed identified areas of concern. If indicated, the students could then engage in an intervention under the guidance of their clinical supervisor. Once the QOL assessment instruments were administered and needs addressed, they moved on to the reflective paper portion of this assignment. The reflective paper was to be written on the process of administering the QOL assessment instruments, while exploring the concept of QOL and the experience of patients who have life-limiting conditions. They were given seven guiding questions, including "did the QOL instruments allow you to communicate more effectively with your patient, in comparison to other patients you cared for?" and "did you gain insight into your patients' lived experience and QOL?" The papers were eight to ten pages in length. 
For the assignment, students were expected to use the following QOL assessment instruments: the Edmonton Symptom Assessment System (ESAS-r) (Bruera, Kuehn, Miller, Selmser, \& Macmillan, 1991) for symptom assessment and the McGill Quality of Life Questionnaire-Revised (MQOL-R) (Cohen, Mount, Strobel \& Bui, 1995). The ESAS-r is a patientreported instrument originally developed for patients suffering from cancer but that is also widely used for individuals who have life-limiting illnesses or are in palliative care. The instrument helps patients report on the presence and severity of various symptoms like nausea, anxiety, tiredness, feeling of wellbeing, and shortness of breath, among others. The questions asked follow a format where patients circle the number, on a scale from 0 (no symptom) to 10 (worst possible symptom), that best describes how they feel "right now" about the specific symptom. The McGill Quality of Life Questionnaire-Revised (MQOL-R) is a multidimensional tool that includes 14 items that measure physical, psychological, existential, and relationship domains. Patients are asked to evaluate significant relationships, stress, sense of control, achievement of their life goals, and meaning of life, over the past 2 days, using a scale that ranges from 0 to 10 with different anchors for each item. The MQOL-R was developed specifically for people with life-threatening illnesses.

The inclusion criteria for this assignment was a patient with a chronic life-limiting condition such as cancer, COPD, HF, MS, CVA, or general frailty due to advanced age combined with a major surgical procedure (for example, an 85-year-old patient with a hip fracture). To identify patients whose conditions are life-limiting, students were encouraged to reflect on the "surprise question" by asking themselves: "Would I be surprised if this patient died in the next year?" (Weissman \& Meier, 2011). The exclusion criterion was any patient with advanced dementia or significant cognitive deficits. In preparation for this assignment, one of the authors (RS) presented and led a class discussion on QOL assessments at the beginning of the term and again halfway through. The students were then presented with the QOL assessments they would be using along with the corresponding assignment described above.

\section{Methods}

We employed the qualitative method of interpretive description (Thorne, 2016), which seeks out associations, relationships, and patterns within the collected data because it recognizes that the applied research mind is not satisfied with "pure" description (Thorne, 2016). As aptly explained by Thorne,

[Interpretive description] challenges the scholar to look below the self-evident within the practice phenomenon under consideration-to document patterned and thematic insights derived from examples of an entity and to reconfigure what is found into a form that has potential to shift the angle of vision with which one customarily considers it (Thorne, 2016, p. 57).

This approach generates knowledge that is of practical importance to the applied disciplines, in this case nursing, and their unique social mandate. We designed our study to address the aforementioned question by analyzing students' reflective writing regarding the introduction of a QOL assessment assignment into a senior-level undergraduate clinical nursing education course.

\section{Recruitment and Sampling}

Incorporating QOL assessments into nursing education was carried out at a midsized university in a four-year baccalaureate on-campus program in western Canada, with fourth-year 
students in their surgical clinical. Of the class of 44 students $87.8 \%$ were female and $12.2 \%$ were male, $82.9 \%$ were between the ages of $20-24,7.3 \%$ between the ages of $25-29,4.9 \%$ between the ages of 30-34, and $4.9 \%$ were 40 and above. After we obtained ethics approval and the class was completed, 30 out of 44 students provided written consent for the analysis of their reflective papers and use in this study.

\section{Data Collection and Analysis}

At the end of the term, after the students had received their marks for the reflective assignment, the papers, with all names and identifying information removed, were given to another colleague familiar with the assignment to prepare them for qualitative analysis. Each reflective paper was read by the first author (who was also the course instructor) and the second author, who in keeping with interpretive description (Thorne, 2016) jointly identified patterns that represented the different experiences and perspectives of the undergraduate nursing students. The authors, to interpret emerging themes, then discussed these patterns. The assignments were reread to verify and further develop emerging themes. Through this process, six themes were identified.

\section{Results}

Students expressed mixed perspectives regarding the use of QOL assessment instruments, which were organized according to the following six thematic patterns: (a) student expectations and patient responses, (b) comfort level using QOL assessment instruments, (c) therapeutic communication person-centred (d) putting the patient first - prioritizing care from the patient's point of view, (e) insight into the lived experience of patients, and (f) use of a nurse's time.

\section{Student Expectations and Patient Responses}

In the assignment, students were to compare their knowledge of the patient's issues with the knowledge gained from the QOL assessment and note any improved understanding or incongruence. Most students identified improved understanding of the patient's conditions as a result of using QOL assessments, evidenced by the following statements: "I discovered that [the patient] had better resilience than I thought he had," and "I would not have known that the patient had experienced any anxiety." Many also reflected on an incongruence between their assumptions and what the patient reported. One student said: "I was surprised that he was not more concerned about his physical health." Another said: "I thought it would be realistic that this man would be depressed or angry or withdrawn when I introduced myself to him, but he was quite the opposite." A few students felt the patient responses were what they expected, as expressed in the following quote: "The patient's prioritized concerns lined up with the concerns that I identified."

\section{Comfort Level in Using Quality of Life Assessments}

The majority of the students identified feeling comfortable in using the QOL assessments. One student wrote, "These questions gave me an opportunity to learn a lot about my patient and her health needs in a natural and easy way." Another wrote, "I felt comfortable in administering the instruments because my patient responded positively when asked if she was willing to participate." A few, however, felt uncomfortable asking questions about emotional, psychological, or existential concerns. One student said: "I felt slightly uncomfortable... I felt as though I was making my patient feel like he was a project." The following quote exemplifies how a student expressed concerns about crossing personal boundaries: "I was nervous... because I didn't want my patient to feel like I was crossing his boundaries by asking him such a personal question when he hadn't known me for very long." Another student thought that asking these deeper questions 
could cause the patient pain: "I felt bad asking him about the future knowing that it was causing him pain to talk about it." Although several expressed discomfort about the possibility of crossing the personal boundaries of the patient, the majority of students felt comfortable with using the QOL assessments in their patient care.

\section{Therapeutic Communication - Patient centred}

Students were asked if the use of the QOL assessments allowed them to communicate more effectively with their patients in comparison to other patients for whom they cared. A few students questioned whether there was an improvement in therapeutic communication. One student stated, "Personally, I did not notice a difference in communication when using the assessment tools. I think I am able to assess if the patient needs more nursing care or if they need to be referred for help from other disciplines." However, most students saw the use of QOL assessments as a beneficial to therapeutic communication. One student said, "I was able to have an in-depth and personal conversation with my patient that I otherwise would not have." A second student stated: "I learned the value of simply sitting with a patient and being able to allow them to speak and be heard in their vulnerable state." Another student identified an increased connection: "This tool fostered a level of connection that I did not have with other patients." Although some students felt they did not need the QOL assessments to facilitate therapeutic communication, most felt that the use of these assessments increased therapeutic communication; none of them identified that it was detrimental to it.

\section{Putting the Patient First: Prioritizing Care from the Patient's Point of View}

As part of the assignment, students were expected to prioritize and list the challenges and concerns of their patients. Based on the information gathered from the instruments, they were then to identify potential interventions and resources (both in hospital and community) to address the patient identified challenges or concerns. Many students identified the importance of involving the patient in their own care and that the use of QOL assessments helped them provide care according to the patient's identified priorities. One student said:

I have come to realize the importance of assessing the quality of life for our patients in the clinical setting. Including our patients in developing a care plan and prioritizing interventions can assist them in feeling a sense of control and allow them to voice their concerns.

Another student felt that the use of QOL assessments helped to provide person-centred care by reorienting care to what is important to the patient, which may be different from the student's assumed priorities:

For example, going into this assignment, I was certain smoking and alcohol cessation would be the top priority. I assumed my patient would feel alienated and lonely, and he would need significant help to feel socially fulfilled. However, by actually assessing my patient's perceived quality of life, I saw that I was wrong in these assumptions."

Overall, students felt that the QOL assessments assisted them in prioritizing care from the patient's point of view.

\section{Insight into the Lived Experience of Patients}

The students were asked whether the QOL assessments helped them gain insight into the patient's lived experience and QOL. Many students identified increased insight with these 
assessments; one student stated, "I learned a lot about who my patient was as a person, and this helped me to understand why he had certain concerns." Another student discussed his or her increased insight with the patient in-depth:

The assessments did help solidify what issues this lady was going through and how she felt about her own quality of life. Behind the veneer of laughter and jokes, there was real physical and social pain she experienced which impacted the rest of her life... [the use of QOL assessments] allowed for a deeper understanding of how she was truly coping with the adjustments. I was able to understand her situation more and see beyond the "complaining, needy, grumpy lady" she had been framed as.

However, although the majority identified that QOL assessments increased their insight into the patient's lived experience, a few students felt that they did not. They felt that their communication and assessment skills were sufficient to gain this insight and that the QOL assessments were difficult to implement, time consuming, and could be considered invasive.

\section{Use of the Nurse's Time}

The focus of the assignment was not a critique of the instruments; however, when asked if they would use these tools in their future practice, many of the students identified time as the major barrier to the use of QOL assessments. One wrote, "I recognize the benefits the assessment has to offer, although as a nurse caring for four to five patients at a time I cannot see or comprehend how this is manageable." Another student stated, "It is not beneficial to give the patient this assessment, when you only have five minutes to talk with them about it." A third student identified, "The application of QOL assessments are time consuming, and in my case, did not give a great number of new concerns in comparison to traditional assessments." On the other hand, some students felt that the QOL instruments were a valuable and worthwhile use of time. One student said that the use of these assessments would even save time:

The time spent would undoubtedly benefit the patient in their hospital experience... knowing from the outset what concerns the patient is experiencing saves resources and time from being spent later on when preventable complications may occur.

Overall, although most of the students viewed lack of time as a major barrier in using QOL assessments, a few did identify that the time spent conducting QOL assessments with the patient was worthwhile and could possibly even save time in the long term. Most students viewed the assignment as a positive and valuable learning experience. Upon reflection, they felt that it increased therapeutic communication between them and their patient, gave them insight into the patient's lived experience, and helped them prioritize care from the patient's point of view. Many were surprised at how their expectations of patient priorities were often not what the patient identified during the QOL assessments. Comfort level using the assessments was good for most; however, many identified time as the biggest constraint.

\section{Discussion}

This study explored the perspectives and experiences of nursing students regarding the use of QOL assessment instruments in their surgical clinical practice. We found that the majority of the students' comments suggested that they recognized the value in the use of QOL assessment instruments in relation to therapeutic communication, putting the patient first, and gaining insight into the patients' lived experiences. Although a large number of students acknowledged they were

comfortable using the QOL assessment instruments with their patients, the most common and 
significant barrier identified was a perceived lack of time. Despite not working at a full RN load, they still felt that there was not enough time to use the QOL assessment instruments even though many acknowledged that doing so did improve their ability to provide person-centred care.

The QOL assignment provided a valuable learning experience regarding the use of QOL assessments. There was also a noticeable shift in the students' perceptions of person-centred care from the first discussion on QOL assessments at the beginning of the term and again halfway through. This shift in perceptions could be attributed to the fact that the assignment was a reflective paper. Critical reflection, as one of the key elements of transformational learning, helps students better understand their own perspectives and develop critical thinking (Kennison, 2006). By asking students to critically reflect on their own assumptions, the clinical instructors provided the students with the opportunities to question their own views on specific ideas or issues (Melrose, Park, \& Perry, 2013).

\section{Recommendations}

It is recommended that further research be conducted to determine whether this type of reflective assignment improves the competence of students in conducting QOL assessments and providing person-centred care.

Management and health care teams need to understand the value of QOL assessments in promoting person-centred care and their responsibility in having these discussions with their patients. Greenhalgh et al. (2005) note that education alone was not enough to change behaviour regarding QOL assessments, and Detmar et al. (2001) identify that the discussion of QOL issues happens when the clinician feels a responsibility to do so. The recommendation is that QOL assessments not only be taught more explicitly throughout nursing education, but that they also be taught as a responsibility of the nurse and reinforced as an integral part of everyday nursing practice. Although further research is needed, we anticipate that starting this discussion in undergraduate nursing education will also reinforce the value of QOL assessments to existing nursing staff in their everyday practice, along with hopefully changing the culture of care with the influx of new RNs educated to promote and facilitate QOL assessments.

When approaching nursing curriculum development, we believe that person-centred care should be embedded within several courses and incorporated across the curriculum. The recommendation is that person-centred care and QOL assessments are incorporated earlier in the curriculum and threaded through the various classroom and clinical settings, starting in the first year of an undergraduate nursing program. Knowledge needs to be gained on how to facilitate QOL assessments, how to implement care based on the knowledge gained, and how to evaluate care based on the feedback given. Competence needs to increase in administering these instruments, reviewing the following assessments, and then care planning. It is hoped that incorporating QOL assessments early in the curriculum will not only improve knowledge and competence regarding their use, but also improve attitudes helping future nurses recognize the value of using standardized tools as part of the process of person-centred care.

\section{Limitations}

The most apparent limitation of this study is that it only involved students in one class at one university. As a result, there was limited representation of students in different contexts and with different backgrounds (e.g., cultural, gender) and perspectives. Moreover, by not interviewing the students and instead drawing on their reflective writing assignment, we were not able to probe 
for deeper understandings. It is our hope that this preliminary study will catalyze further research in this area.

\section{Conclusion}

This study has shown the potential value of incorporating QOL assessments into clinical learning experiences. However, there is a gap in the literature and nursing education regarding the use of QOL assessment instruments. Education in undergraduate nursing programs on how to use and act upon QOL assessments in clinical practice is the first step toward recognizing a patient's priorities and truly putting the patient first. As one student reflected:

The quality of life assessments are effective because they provide a patient's point of view and they put the patient first. We all make assumptions and it's very difficult to assess mental, social, and human conditions. Patients may have lived with a condition for a long time and they may be very used to dealing with it. Quality of life assessments discover what really matters to the patient and how to prioritize treatment plans to meet them. 


\section{References}

Antunes, B., Harding, R., \& Higginson, I. J. (2014). Implementing patient-reported outcome measures in palliative care clinical practice: A systematic review of facilitators and barriers. Palliative Medicine, 28(2), 158-175. https://doi.org/10.1177/0269216313491619

Barham, L., \& Devlin, N. (2011). Patient-reported outcome measures: Implications for nursing. Nursing Standard, 25(18), 42-45. https://doi.org/10.7748/ns2011.01.25.18.42.c8233

Basch, E., \& Abernethy, A. P. (2011). Supporting clinical practice decisions with real-time patient-reported outcomes. Journal of Clinical Oncology, 29(8), 954-956. https://doi.org/10.1200/jco.2010.33.2668

Bruera, E., Kuehn, N., Miller, M. J., Selmser, P., \& Macmillan, K. (1991). The Edmonton Symptom Assessment System (ESAS): A simple method for the assessment of palliative care patients. Journal of Palliative Care, 7(2), 6-9.

Catania, G., Beccaro, M., Costantini, M., Ugolini, D., De Silvestri, A., Bagnasco, A., \& Sasso, L. (2015). Effectiveness of complex interventions focused on quality-of-life assessment to improve palliative care patients' outcomes: A systematic review. Palliative Medicine, 29(1), 5-21. https://doi.org/10.1177/0269216314539718

Choy, S. (2009). Transformational learning in the workplace. Journal of Transformative Education, 7(1), 65-84. https://doi.org/10.1177/1541344609334720

Cohen, S. R., Mount, B. M., Strobel, M. G., \& Bui, F. (1995). The McGill Quality of Life Questionnaire: A measure of quality of life appropriate for people with advanced disease. A preliminary study of validity and acceptability. Palliative Medicine, 9(3), 207-219. https://doi.org/10.1177/026921639500900306

Cranton, P. (2006). Fostering authentic relationships in the transformative classroom. New Directions for Adult and Continuing Education, 2006(109), 5-13. https://doi.org/10.1002/ace.203

Cranton, P., \& Wright, B. (2008). The transformative educator as learning companion. Journal of Transformative Education, 6(1), 33-47. https://doi.org/10.1177/1541344608316961

Dawson, J., Doll, H., Fitzpatrick, R., Jenkinson, C., \& Carr, A. J. (2010). The routine use of patient reported outcome measures in healthcare settings. British Medical Journal, 340, c186. https://doi.org/10.1136/bmj.c186

Detmar, S. B., Muller, M. J., Wever, L. D., Schornagel, J. H., \& Aaronson, N. K. (2001). Patientphysician communication during outpatient palliative treatment visits: An observational study. JAMA, 285(10), 1351-1357. https://doi.org/10.1001/jama.285.10.1351

Ekman, I., Swedberg, K., Taft, C., Lindseth, A., Norberg, A., Brink, E., ... Sunnerhagen, K. S. (2011). Person-centered care-Ready for prime time. European Journal of Cardiovascular Nursing, 10(4), 248-251. https://doi.org/10.1016/j.ejcnurse.2011.06.008

Etkind, S. N., Daveson, B. A., Kwok, W., Witt, J., Bausewein, C., Higginson, I. J., \& Murtagh, F. E. (2015). Capture, transfer, and feedback of patient-centered outcomes data in palliative care populations: Does it make a difference? A systematic review. Journal of 
Pain and Symptom Management, 49(3), 611-624.

https://doi.org/10.1016/j.jpainsymman.2014.07.010

Fayers, P. M., \& Machin, D. (2013). Quality of life: The assessment, analysis and interpretation of patient-reported outcomes (2nd ed.). Chichester, UK: John Wiley \& Sons.

Greenhalgh, J. (2009). The applications of PROs in clinical practice: What are they, do they work, and why? Quality of Life Research, 18(1), 115-123. https://doi.org/10.1007/s11136-008-9430-6

Greenhalgh, J., Long, A. F., \& Flynn, R. (2005). The use of patient reported outcome measures in routine clinical practice: Lack of impact or lack of theory? Social Science \& Medicine, 60(4), 833-843. https://doi.org/10.1016/j.socscimed.2004.06.022

Greenhalgh, J., \& Meadows, K. (1999). The effectiveness of the use of patient-based measures of health in routine practice in improving the process and outcomes of patient care: A literature review. Journal of Evaluation in Clinical Practice, 5(4), 401-416. https://doi.org/10.1046/j.1365-2753.1999.00209.x

Keating, S. B. (2006). Curriculum development and evaluation in nursing. Philadelphia, PA: Lippincott Williams \& Wilkins.

Kennison, M. M. (2006). The evaluation of students' reflective writing for evidence of critical thinking. Nursing Education Perspectives, 27(5), 269-273.

Marshall, S., Haywood, K., \& Fitzpatrick, R. (2006). Impact of patient-reported outcome measures on routine practice: A structured review. Journal of Evaluation in Clinical Practice, 12(5), 559-568. https://doi.org/10.1111/j.1365-2753.2006.00650.x

McWilliam, C. L. (2007). Continuing education at the cutting edge: Promoting transformative knowledge translation. The Journal of Continuing Education in the Health Professions, 27(2), 72-79. https://doi.org/10.1002/chp.102

Melrose, S., Park, C., \& Perry, B. (2013). Teaching Health Professionals Online: Frameworks and Strategies. Edmonton, AB: Athabasca University Press.

Melrose, S., Park, C., \& Perry, B. (2015). Creative clinical teaching in health professionals. Retrieved from http://epub-fhd.athabascau.ca/clinical-teaching/

Mezirow, J. (1997). Transformative learning: Theory to practice. New Directions for Adult and Continuing Education, 1997(74), 5-12. https://doi.org/10.1002/ace.7401

Ohlen, J., Reimer-Kirkham, S., Astle, B., Hakanson, C., Lee, J., Eriksson, M., \& Sawatzky, R. (2017). Person-centred care dialectics-Inquired in the context of palliative care. Nursing Philosophy, 18(4). https://doi.org/10.1111/nup.12177

Ousey, K., \& Cook, L. (2011). Understanding patient reported outcome measures (PROMs). British Journal of Community Nursing, 16(2), 80-82. https://doi.org/10.12968/bjen.2011.16.2.80

PROQUOLID [Database]. (2019). Retrieved from https://eprovide.mapi-trust.org/

Santana, M. J., Haverman, L., Absolom, K., Takeuchi, E., Feeny, D., Grootenhuis, M., \& Velikova, G. (2015). Training clinicians in how to use patient-reported outcome measures 
in routine clinical practice. Quality of Life Research, 24(7), 1707-1718. https://doi.org/10.1007/s11136-014-0903-5

Snyder, C. F., Aaronson, N. K., Choucair, A. K., Elliott, T. E., Greenhalgh, J., Halyard, M. Y., ... Santana, M. (2012). Implementing patient-reported outcomes assessment in clinical practice: A review of the options and considerations. Quality of Life Research, 21(8), 1305-1314. https://doi.org/10.1007/s11136-011-0054-X

Stansberry, S. L., \& Kymes, A. D. (2007). Transformative learning through "Teaching with technology" electronic portfolios. Journal of Adolescent \& Adult Literacy, 50(6), 488496. https://doi.org/10.1598/jaal.50.6.6

Tennant, M. (2005). Transforming selves. Journal of Transformative Education, 3(2), 102-115. https://doi.org/10.1177/1541344604273421

Thorne, S. (2016). Interpretive description: Qualitative research for applied practice (Vol. 2). New York, NY: Routledge.

Weissman, D. E., \& Meier, D. E. (2011). Identifying patients in need of a palliative care assessment in the hospital setting: A consensus report from the Center to Advance Palliative Care. Journal of Palliative Medicine, 14(1), 17-23. https://doi.org/10.1089/jpm.2010.0347

World Health Organization. (2017). Health statistics and information systems. Retrieved from www.who.int/healthinfo/survey/whoqol-qualityoflife/en/

Zhao, J., Gao, S., Wang, J., Liu, X., \& Hao, Y. (2016). Differentiation between two healthcare concepts: Person-centered and patient-centered care. International Journal of Nursing Sciences, 3(4), 398-402. https://doi.org/10.1016/j.ijnss.2016.08.009 